\title{
Interprofessional Doctoral Programs: Challenging Disciplinary Constructs
}

\section{Jennifer Harrison}

School of Social Work, College of Health and Human Services, Western Michigan University, Kalamazoo, MI 49008-5354, USA

\section{Abstract}

Interprofessional education is a popular term, and becoming a way for health science colleges to differentiate themselves in the market. And yet, truly interprofessional learning and teaching is hard to accomplish, as we are all quite dedicated to our disciplinary constructs, learning approaches, and even language. One interdisciplinary health sciences doctoral program is discussed for its successes and struggles in having a truly interprofessional approach for mid-career occupational therapists, social workers, nurses, speech pathologists, physical therapists, and vision rehabilitation specialists. This approach involves the critical evaluation of theories and philosophical frameworks that inform curriculum, teaching, and structure, and an awareness of the unique qualities that adult learners bring to the task. Innovation in the delivery of course content forces us to examine not only our andragogic framework, but also the methodology of teaching to enhance access and prepare adults for learning and doing in the 21 st century.

\section{My Experience with Interprofessional Education}

The year I turned $40 \mathrm{I}$ also returned to school as a student for the first time in over 15 years. I had been a practicing social worker and chemical addictions counselor for many years. I had worked on interprofessional teams in hospitals, mental health centers, and military service centers. I had been a teacher, trainer, and even a principle investigator for a large federal grant. And I thought I knew most of what it was to be interprofessional in my work, and in my learning. Being a student and now alumni of an interdisciplinary doctoral program in health sciences taught me a lot, but one of my first lessons was how little I understood interprofessional education and practice. The journey, which continues, is the work of having my research, my teaching, and my worldview become interprofessional.

\section{Adult Learning and Why It Matters}

In some ways it is an odd thing to continue with education as an adult. Centuries ago that luxury did not exist. Children were taught in the basic competencies they would need to be able to function in the home or workplace. Education was further limited by the social context that you were born into, and the degree of privilege you had to indulge in learning. And yet today we have a more educated populous than ever before, and adult learning is considered essential to enter many fields, let alone advance. Our educational system is also becoming more available to populations traditionally excluded, with ethnic minority students accounting for $45 \%$ of high school graduates by 2020 , up substantially from $38 \%$ in 2009 [1]. The purpose of adult learning, and post-secondary learning, has changed over the last 100 years, and the purpose and even mission of higher education will need to change with it. The Association of College and Research Libraries has the following definition and call to action for adult learning [2].

Developing lifelong learners is central to the mission of higher education institutions. By ensuring that individuals have the intellectual abilities of reasoning and critical thinking, and by helping them construct a framework for learning how to learn, colleges and universities provide the foundation for continued growth throughout their careers, as well as in their roles as informed citizens and members of communities.

The fact that adult learning here is seen within a social construct, and enabling growth of citizens and community members, is of crucial note. We are no longer teaching adults only enough to operate a machine or a plow, but to learn how to learn, and thereby challenge the social order. In addition, although pedagogy can still frequently be focused on content delivery and instructor philosophy, andragogy is necessarily more learner-centered.

Most of us attend college to enter our profession within our adulthood, and yet learning as traditionally-aged college students, and learning as mid-career professionals, can be quite different experiences. Similarly, it is not until we enter practice with a particular disciplinary approach, whether it be social work, occupational therapy, or nursing, that we often realize the degree of socialization in our profession that comes with our professional education, and that "professionalism is actually a deterrent to collaboration, since each profession has its own set of norms, codes, and other 'professioncentric' characteristics," [3]. This acknowledgement comes when we begin to work in interdisciplinary fields with other professionals. For many of us, practice in at least multi-disciplinary settings, if not interprofessional ones, is the way we practice. However, truly interprofessional education is a rarer thing for a reason, in that it pushes against our well-established social constructs of disciplinary education. In this setting, Interprofessional education leverages Critical Social Theory (CST), of the belief that social structures, as social constructs, confer power [4], and that teaching students to critically analyze social constructs in the form of policies, politics, and even worldview will give them the tools to effectively challenge those constructs, which at the same time recognizing themselves as actors of privilege within those constructs. CST is fleshed out by one of the preeminent theorists in the field, Paulo Freire, who spoke about the role of teacher as a critical theorist in the teaching process, "those who authentically commit themselves to the people must reexamine themselves constantly" [5]. Teaching and learning in an interprofessional settings allows us to advocate alongside our students and clients, by recognizing and challenging the power structures that promote oppression and injustice.

*Corresponding Author: Dr. Jennifer Harrison, School of Social Work, College of Health and Human Services, Western Michigan University, Kalamazoo, MI 49008-5354, USA; E-mail: jennifer.harrison@wmich.edu

Citation: Harrison J (2017) Interprofessional Doctoral Programs: Challenging Disciplinary Constructs. Int J Community Fam Med 2: 126. doi: https://doi. org/10.15344/2456-3498/2017/126

Copyright: () 2017 Harrison. This is an open-access article distributed under the terms of the Creative Commons Attribution License, which permits unrestricted use, distribution, and reproduction in any medium, provided the original author and source are credited. 


\section{Interprofessional Doctoral Education}

Interprofessional experiences in courses, study abroad, and practical internships have become more of a demand amongst employers of allied health professionals. However, this is typically limited to undergraduate preparation of allied health professionals for a practice experience that will be interdisciplinary by design.

Interprofessional doctoral education for health professionals including occupational therapists has some examples to draw from, including a blended (on-line and in-person coursework) program at Virginia Commonwealth University [6], and an interdisciplinary program in neuroscience at Georgetown University [7]. The Interdisciplinary Health Sciences (IHS) $\mathrm{PhD}$ program at Western Michigan University offers another example of mid-career, researchintensive interprofessional doctoral education, structured to train allied health professionals in an intentionally interdisciplinary setting.

The IHS PhD programs provides several of the key components associated with success in interprofessional teaching and structure. The interprofessional nature of the program begins with the faculty and student selection. No more than two faculty members represent any one discipline, and include occupational therapy, nursing speech and hearing sciences, higher education, public health, and epidemiology. Students are admitted in a cohort in even years, and the student cohorts likely self-select for their interest in interprofessional education as seen in Hammer and co-authors [3], and no more than three students from any one allied health discipline are selected in any one cohort. As in Goldberg, Clement, \& Cotter [6], students also self-select from a group of older, highly motivated, and highly self-disciplines professionals with several years of existing clinical practice, and often teaching, grant development, or policy analysis experience as well.

The program is structured in four main areas: research, teaching, policy, and grants, with courses during the first two years taken as a cohort in a blended learning environment, with two week intensive courses in Summer, and one course taught over three weekends and another taught fully on-line for each Fall and Spring semester, augmented by nine cognate credits determined by students and advisors based upon research interests. Some of the concerns with distance education of decreased instructor-student and studentstudent rapport and interaction [7] may be eliminated by the cohort model, as students and instructors know each other from traditional in-person coursework prior to and simultaneously on-line coursework. Following structured coursework, students complete four comprehensive examinations, and then a dissertation of original research. The entire program is designed to be completed in four years, and the range of completion is three - seven years.

Throughout the program, there are built environment structures that enforce interprofessional work. Students from the same discipline are almost never in a group together, ensuring that projects in health ethics, quantitative analysis, and policy evaluation will all be completed in interprofessional settings. As a student, one of the most noteworthy aspects of learning was that even though I thought I knew about other professions, I lacked all but the most basic language and history of disciplines outside of my own. This was particularly noteworthy in our shared writing. I, like many, had ascribed to the "abiding myth (that) appears to exist among academics that writing is a solitary process and must, by its very nature, be undertaken alone, even though the basis of all academic research in peer review," [9]. Group writing and review, whether in class assignments completed together, or in peer formed review and writing weekends that we organized on our own as students, gave me a better understanding of how to explain research in non-discipline specific ways, to get away from my disciplinary nomenclature, and to be more aware of the social constructs of my professional in needing to justify my perspectives beyond simple advocacy. This was particularly useful in developing new skills in research, and in developing the ability to "optimize the impact of research investments on health outcomes," [10].

There are two examples that stick out to me of how this interprofessional structure benefited me as a developing researcher in health sciences. In one course, a small group of a speech pathologist, occupational therapist, nurse, dietitian, and myself were tasked with analyzing data from a large secondary data set using linear and logistic regressions, and developing a poster of our data. We choose to analyze variables related to breastfeeding, including age, race/ethnicity, and income. After discussions of our clinical practice experience with breastfeeding and mother/infant care, and our personal experiences with breast-feeding, we went about analyzing our variables. In our processes we decided to justify the variables we were testing before running the analysis. What difference would it make if younger women breastfed less (which is the case), or if race interacted with family income on length of breast-feeding. This forced us to think in an interprofessional manner about the possible outcome impact before running the statistics, so we would think about what difference that analysis made, instead of reverse engineering from statistical significance to variables of interest.

In a second course, one on qualitative research and ethics, we were put into small groups to analyze and discuss interviews from missionary nurses practicing in the Middle East with pregnant and parenting women patients. My partner was from the Middle East, with a background in hospital care. When discussions of the different interactions between healthcare professionals and their female clients, as well as their male family members, emerged, I was admittedly ready to get on my "social justice" high horse, commenting on the injustices and limitations women faced in countries with more restrictive gender norms. It was perhaps only my respect for my student colleague from two years of working with him, that allowed me to check my own sense of cultural power before speaking up. The research we were able to do together was better for my holding my tongue, and actually enabled a more thorough discussion of medical ethics related to pregnancy care in Islam, as well as end of life care from different perspectives.

\section{The Role of Interprofessional Learning}

None of us as health professionals, whether in occupational therapy, medicine, or social work, are immune to their professional identity to the middle class values that are often their own background. However, interprofessional education can enable us to view our own position, relative to other professionals, to our clients and communities, and to become stewards of new professions, by transforming the communication of knowledge within and between professions [7]. Through interprofessional education at any level, but particularly at the doctoral level, we can better distribute the social goods of health, described in CST as the concept of distributive justice, the equitable distribution of 'primary social goods' including liberty and opportunity [11]. One of the voices on distributive justice, John Rawls (a contemporary of John Locke and Jean-Jacques Rousseau), even spoke to our own social position; 
Citation: Harrison J (2017) Interprofessional Doctoral Programs: Challenging Disciplinary Constructs. Int J Community Fam Med 2: 126. doi: https://doi. org/10.15344/2456-3498/2017/126

Page 3 of 3

None of us deserves the advantages conferred by accidents of birth - either the genetic or social advantages. These advantages from the 'natural lottery' are morally arbitrary, because they are not deserved, and to let them determine individual opportunity - and reward and success in life - is to confer arbitrariness on the outcomes [12].

The interdisciplinary health sciences $\mathrm{PhD}$ program has provided me with a sound grounding to begin the journey as a teacher and researcher into distributing health with my interprofessional colleagues, hopefully more effectively.

\section{Competing Interests}

The author declares that he has no competing interests.

\section{References}

1. Hoover E (2013) Wave of diverse college applicants will rise rapidly: Wave of diverse students will constitute nearly half of public high-school graduates, report says, even as number of black students declines. The Chronicle of Higher Education, Jan 10, 2013.

2. Association of College and Research Libraries (2000) Information literacy competency standards for higher education. Chicago, IL.: Author.

3. Hammer D, Anderson MB, Brunson WD, Grus C, Heun L, et al. (2011) Defining and measuring construct of interprofessional professionalism. J Allied Health 41: e49-53.

4. Beatty JE (2009) Philosophy rediscovered: Exploring the connections between teaching philosophies, educational philosophies, and philosophy. Journal of Management Education 33: 99-114.

5. Freire P (1970) Pedagogy of the oppressed. New York, NY: Continuum.

6. Goldberg DG, Clement DG, Cotter JJ (2014) Development and alumn assessment of an interdisciplinary $\mathrm{PhD}$ program offered through a blended learning environment. Journal of Allied Health 40:137-142.

7. Ullrich L, Dumanis SB, Evans TM, Jeannotte AM, Leonard C, et al. ((2014) From student to steward: The interdisciplinary program in neuroscience at Georgetown University as a case study in professional development during doctoral training. Med Edu Online 19: 1-12.

8. Hale LS, Mirakian EA, Day DB (2009) Online vs. classroom instruction Student satisfaction and learning outcomes in an undergraduate allied health pharmacology course. J Allied Health 38: e36-e42.

9. Guerin C, Xafis V, Doda DV, Gillam MH, Larg AJ, et al. (2013) Diversity in collaborative research communities: A multicultural, multidisciplinary thesis writing group in public health. Studies in Continuing Education 35: 65-81.

10. Collisson BA, Benzies K, Mosher AA, Rainer KJ, Tanaka S, et al. (2011) Knowledge translation: Principles and practicalities for trainees within interdisciplinary health research teams. Clin Invest Med 34: e366-e369.

11. Wakefield JC (1988) Psychotherapy, distributive justice, and social work Social Service Review 62: 187-210.

12. Rawls J (1971) A theory of justice. Cambridge, MA: Belknap Press of Harvard University Press. 